\title{
Mild to Moderate Anisopoikilocytosis
}

National Cancer Institute

\section{Source}

National Cancer Institute. Mild to Moderate Anisopoikilocytosis. NCI Thesaurus. Code C96207.

A test result indicating a mild to moderate degree of anisopoikilocytosis in the peripheral blood. 